\title{
Training service providers on emergency contraception: Lessons learned from an OR study
}

\author{
M.E. Khan \\ Population Council \\ Sharif M.I. Hossain \\ Population Council
}

Follow this and additional works at: https://knowledgecommons.popcouncil.org/departments_sbsr-rh

Part of the Demography, Population, and Ecology Commons, Family, Life Course, and Society Commons, and the Maternal and Child Health Commons How does access to this work benefit you? Let us know!

\section{Recommended Citation}

Khan, M.E. and Sharif M.I. Hossain. 2002. "Training service providers on emergency contraception: Lessons learned from an OR study," FRONTIERS Research Update. Dhaka: Population Council. 


\section{Training Service Providers on Emergency Contraception: Lessons Learned from an OR Study}

\section{Introduction}

The Bangladesh Directorate of Family Planning in collaboration with the Population Council, Pathfinder International and John Snow, Inc. is conducting an operations research project to test the feasibility of introducing Emergency Contraceptive Pills (ECP) in the national family planning (FP) program and to answer several operational questions on how to implement the use of ECP efficiently.

ECPs are increased doses of "regular" oral contraceptive pills (OCP) taken in two doses to avoid pregnancy from unprotected intercourse. The first dose must be taken within 72 hours of unprotected intercourse and the second dose 12 hours after the first dose. The earlier the pills are taken, the more effective they are. The most com-

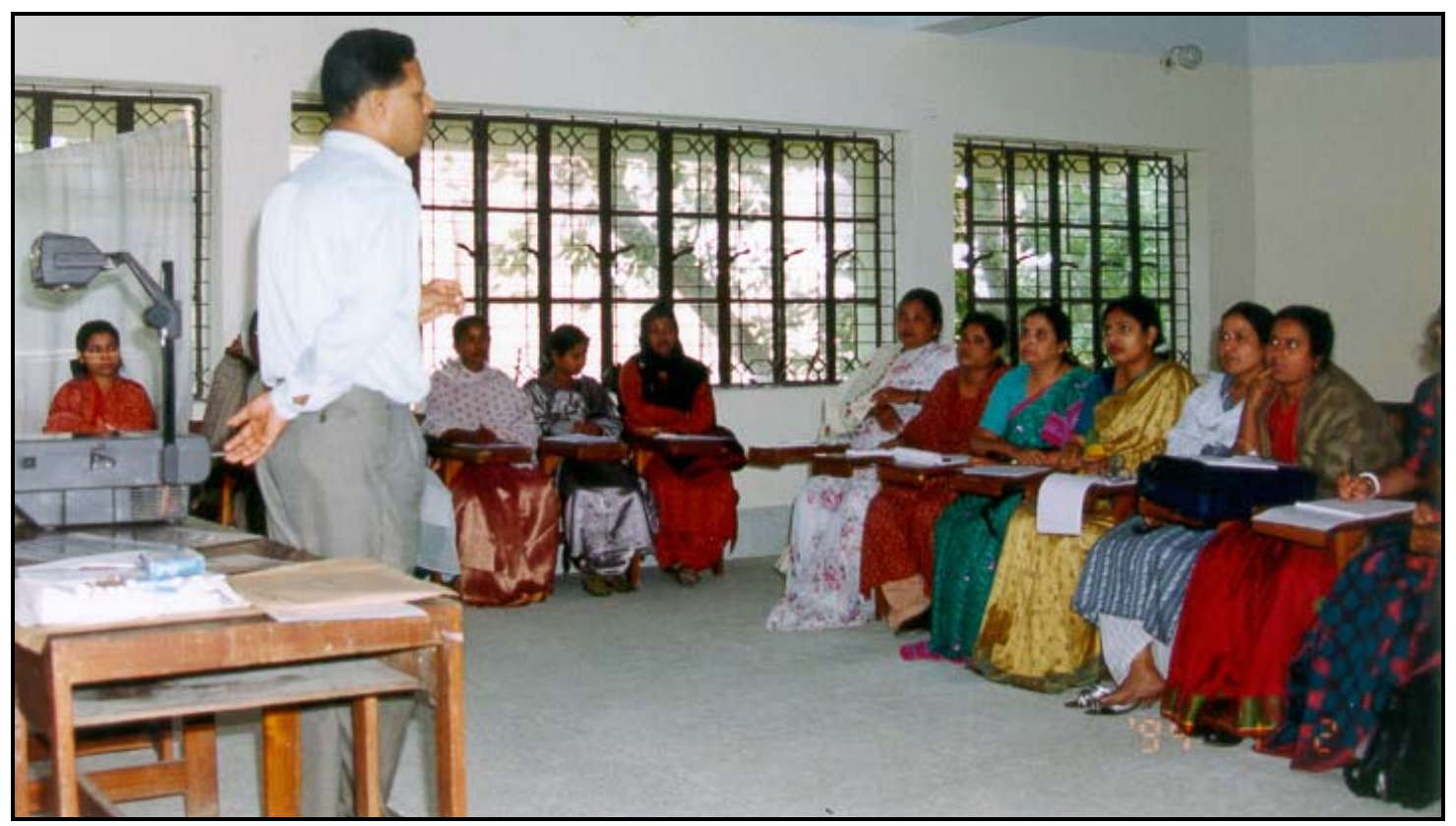

mon ECPs are "combination pills" that contain estrogen and progestin hormones. ECPs containing progestin only are also available (e.g., Postinor 2) which are relatively more effective and have less side-effects than combination pills.

In Bangladesh 1.2 million births are unplanned and the number of MR/abortions is increasing (Box 1). ECP could be a good reproductive health intervention for women since it gives them a chance to avoid unwanted pregnancy. ECP does not induce any abortion. In fact, it helps in reducing the number of abortions. A recent WHO publication indicates that use of ECPs could reduce the induced abortion rate as much as 50 percent (WHO, 2001). 
In Bangladesh, the concept of emergency contraception (EC) is relatively new and there is general lack of knowledge even among doctors (Chowdhury et al. 1998). Thus, training providers will be a critical element for the introduction of ECP. The present feasibility study has been undertaken to answer several operational questions that need to be addressed while introducing the ECP method in the national FP program (see Box 2). The study has been carried out in two districts, Tangail and Mymensingh. For more details on the intervention see Research Update 1 (Khan and Sharif 2001).

\section{Box 1: Emergency Contraceptive Pills: A Reproductive Health Intervention}

- 31 percent of births (1.2 million) in Bangladesh are unplanned.

- There is an increasing trend of MR and illegal abortions.

- 28 percent of the estimated deaths are due to abortionrelated complications.

- Many of these unwanted pregnancies/deaths could be avoided by providing EC as back-up support.

- ECP avoids pregnancy, but it does not induce abortion.

- ECP is $75-88$ percent effective if used in the first 24 hours after unprotected intercourse.

- Any woman can take ECP, even those who were told not to take oral contraceptive pills.

The key factors for introducing ECP are increasing community awareness about the method, making it widely and easily accessible, promoting its appropriate uses, returning clients to regular contraception after using ECP, and managing side-effects, if any. Proper training of the service providers, an effective and sustained educational campaign among potential clients, and a guaranteed regular supply of the pills can help in addressing these issues. Given the low level of education of many grass roots workers, the study sought to assess whether the workers could be trained to provide ECP and correctly inform clients.

This is the second Research Update on the emergency contraception study. It provides details on how providers' training was organ-

Box 2: Operational Questions for Introducing ECP

- Can grass-roots workers be trained and used for providing ECP?

- What should be the content and duration of training?

- Will the trained workers be able to communicate correct information to their clients?

- What is the best way to incorporate ECP training within the existing training program?

ized and evaluated and the lessons learned. This information will be useful when ECP is introduced in the national FP program.

\section{Study Methodology}

The ECP study has been implemented in three phases. In the first phase, several preparatory activities were carried out, such as developing ECP brochures, teaching aids and a trainer's manual and conducting a baseline survey of the providers to assess their knowledge of ECP and their counseling skills. Also, the study used qualitative methods to assess the demand for ECP, potential uses and existing practices that women use to avoid pregnancy after unprotected intercourse (Research Update 1). The second phase was an intervention phase (training of providers and provision of ECP services). The third phase, currently being implemented includes an impact assessment, dissemination of results and utilization of research findings.

\section{Training of Service Providers on Emergency Contraceptive Pills}

Preparatory Work: Before implementing the training, several preparatory steps were taken. These included: 
- Developing training manual.

- Planning and listing learning objectives for each training session.

- Developing overhead transparencies for each session (in Bangla).

- Developing guidelines for organizing "role plays" as a training tool.

- Developing and printing two ECP brochures, one each for the providers and

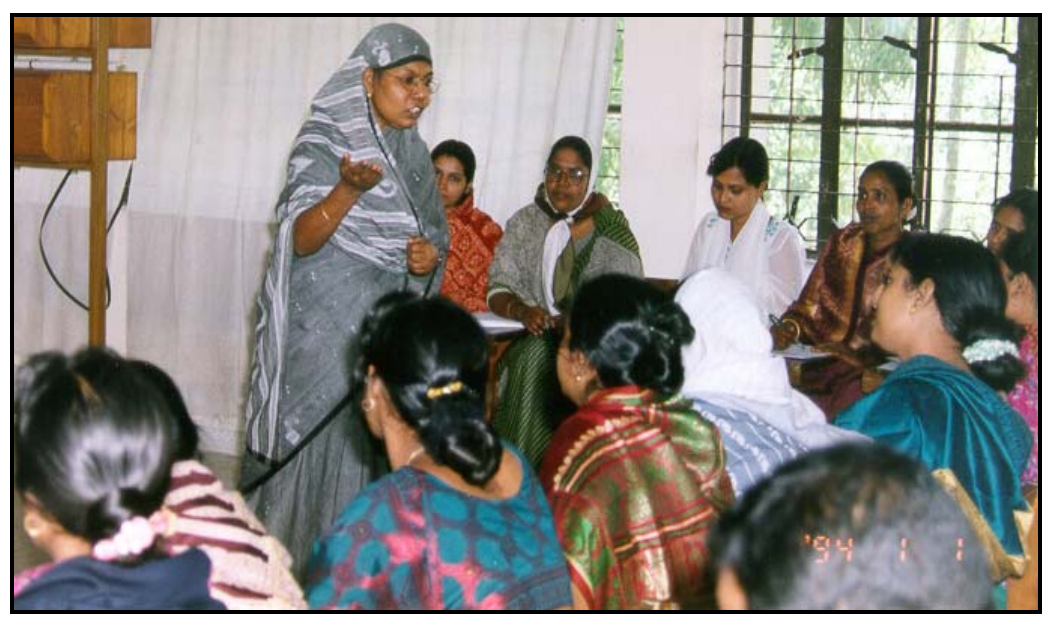
clients (in Bangla).

- Discussing the objectives of the project with trainers, the purpose of the training and the learning objectives for each session.

The training program materials were purposefully standardized and the training was institutionalized in a public training institute in consideration of the future needs for scaling up and introducing ECP in the national FP program. The training program was carefully monitored and evaluated to answer operational issues raised earlier for introducing ECP in the national FP program (Box 2).

Focus of Training: Training was organized for all thana and district levels staff in the NGOs and the government family planning service delivery system. Trainees included: program managers, field supervisors and grass-roots workers.

While all three groups received training on ECP (Box 3 ), the detail and emphasis of the training sessions varied for each group. For grass-roots level providers, in addition to ECP, training included a contraceptive technology update (CTU) and a session on counseling skills. Supervisors received additional training on the importance of supportive supervision (rather than policeing), procedures for monitoring ECP works and using monthly meetings as an opportunity to clarify workers questions about ECP. Orientation of the Program Managers was more comprehensive and centered on the technical details

\section{Box 3: What Was Taught about EC}

- What is EC? When can it be used?

- Dose, interval between doses, time limit, ECP effectiveness and mode of actions.

- Side-effects and their management.

- Care to be taken in counseling on ECP to OCP users.

- Return to regular FP methods after ECP use.

- Possible common questions and answers about ECP use. of ECP and its role as a reproductive health intervention.

Training Organization: The field workers and their supervisors operating in the experimental areas received training at two different times. First, a two-day training was provided. One month after this training, a half-day orientation session was conducted to share their first month experiences of providing EC pills, clients' reactions to the method and to address their questions about ECP, if any (Figure 1). The providers in the control areas given only a one-day, one-time only training. They were given identical training as the providers in the experimental areas on CTU and counseling skills, but nothing was mentioned about ECP or the project activities. All trainings sessions were conducted in collaboration with the District Family Planning Office (DFPO) and the Family Welfare Visitor Training Institute (FWVTI) in Tangail. Selected faculties of FWVTI and DFPO were fully involved in the planning and implementation of the training. Officials from the Directorate of Family Planning and district administration also participated in the training program as resource persons. 
In the first training, each session had a time-bound presentation, role-play, and a question and answer time. The trainers had several rounds of discussion before finalizing session's objectives and contents of the training. As a result, the trainers were clear about the learning objectives of each session and the expected outcome of the session. All the workers were provided with a brochure on ECP developed both for the providers and clients.

The second training session was conducted in a more informal environment and in a question and answer format. The workers were encouraged to share their experiences particularly about the acceptability of the method by the clients, types of questions they asked, problems they faced in addressing the client's questions and their own doubts about ECP, if any. Even though the second orientation on ECP was only a half-day, it was extremely useful because many workers had questions about the method (Box 4). Clarification of their doubts helped in improving their knowledge about ECP and as consequence their counseling with the clients.

Monitoring the Quality of Information Provided to Client: The study used a decentralized monitoring process by providing responsibilities to each partner organization. Special attention was paid to strengthen supportive supervision for monitoring the project activities. Steps taken to monitor the program include:

- Checking workers' knowledge and their provision of ECP services during each field visit by supervisors and program managers. To help supervisors to do this a special check list was prepared.

- Discussing the project activities and clarifying providers' doubts, if any, during the regular monthly meeting of the field staff/depot holders.

- Regular checking of the information on the client's registration form and ensuring that informed consent of the clients is properly obtained to visit their home for a follow-up interview.

\section{Findings}

Background of the Service Provider: All the service providers operating in the study area were provided training. They were mainly paramedics (Family Welfare Visitors, paramedics and Sub-Assistant Community Medical Officers), community health workers (Family Welfare Assistants and depot holders) and their supervisors (Family Planning Inspectors, Senior Service Promoters, Service Promoters, and Community Mobilizers) working in government and NGO family planning programs. Some of the auxiliary staff (pharmacists, counselors and clinic aides) helping in the service delivery were also given the training. 
The baseline survey of the providers revealed that 92 percent of them were female. About 11 percent of them were supervisory level staff. About one-fourth of the providers were above age 40 years. The mean and median age was around 33 and 32 years, respectively. About 13 percent of the workers had only primary or less (1-5 class) level of schooling, 31 percent upto middle school (6-8 class) and 29 percent upto matriculation (9-10 class). The rest (27 percent) had higher level education. Most of them (95 percent) had attended at least one training session on family planning methods.

\section{Impact Assessment of Training: Before} orienting the providers about EC, all FP workers and their supervisors in the study areas $(n=290)$ were interviewed to assess their knowledge and perceptions about EC, use of OCP and counseling skills. The 321 providers who attended the first training on ECP were subjected to a brief post-training test immediately after the training. Finally, the impact of the training and assimilation of knowledge by the workers were evaluated four months after the first training. Both in the baseline survey and the end evaluation, the providers were individually interviewed using a structured questionnaire.

In the baseline survey, out of the 290 workers interviewed, 64 (22 percent) were vaguely aware that Shukhi (regular OCP) could be used to avoid pregnancy from unprotected sex. However, only four of them (1.4 percent) had correct knowledge about the number of doses, number of pills in each dose, interval between the two doses and time limit within which ECP must be taken. None mentioned any other brand of pills that could be used as ECP. Thus, overall knowledge about ECP was almost non-existent among the providers. Most of the providers (67 percent) also mentioned that they frequently received clients who came to them for advice after unprotected sex. The num-

ber of such clients varied between 2-12 in a month. About 91 percent strongly supported introduction of ECP in the national family planning program and hoped that its would reduce increasing demand for abortion services. Most of them believed that women would pay for ECPs if the pills were not provided free (see Figure 2). Similar view was expressed by community members during focus group discussions (see Research Update 1). Many felt that this method should have been made available a long time ago.

\section{Figure 2: Perceptions of FP Workers on Emergency Contraceptive Pills}

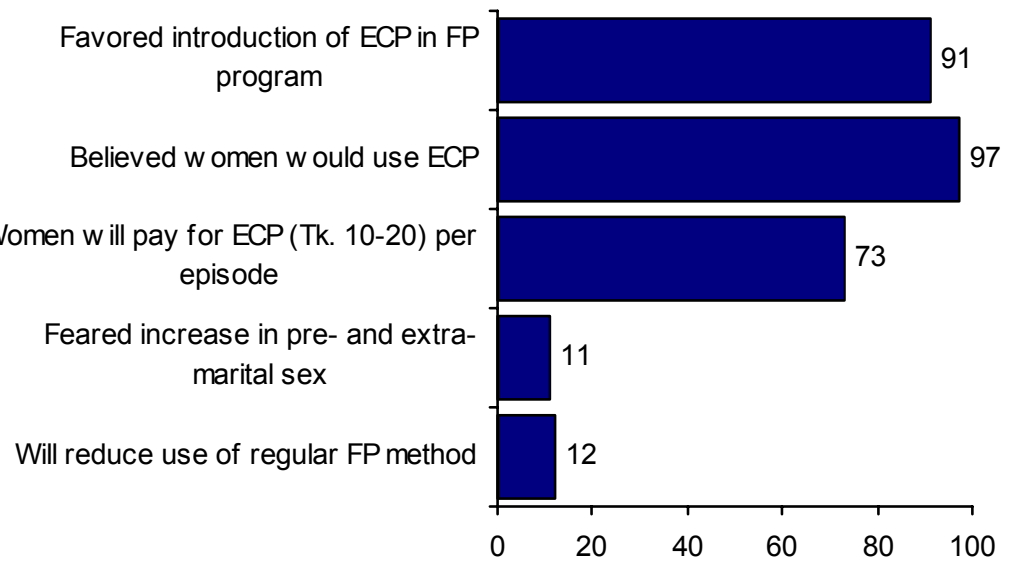

Source: Baseline survey of providers

\section{Box 4: Questions Commonly Asked by Clients}

- Can breast-feeding mothers use ECP?

- What will happen if the second dose is delayed?

- What FP method could be used after using ECP?

- How many days after the 2nd dose of ECP will the woman remain protected against unprotected interurse?

using ECPs?

- Will ECP adversely affect future pregnancy?

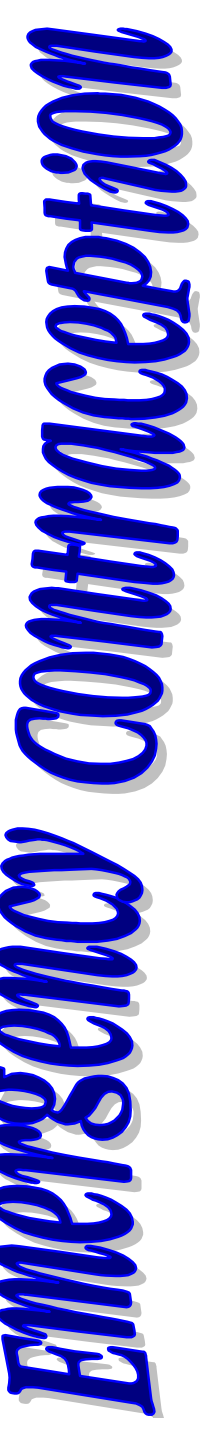


The following comment from a provider about the usefulness of ECP is a typical sentiment:

Many women used to approach us for advise after an unprotected sex. Previously we were helpless. We used to say wait and see up until the start of the next menstrual period. Now, we can advice them what to do. It's a useful method. The clients are happy that they could protect themselves from unwanted pregnancy. We are happy to be useful to them.

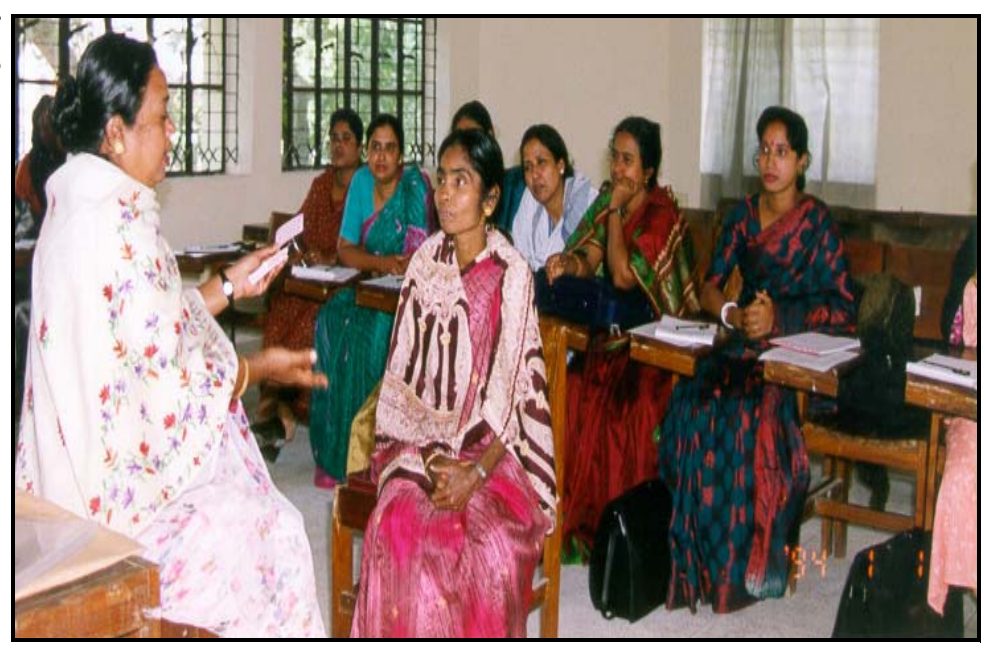

Role Play During Training Session

Analysis of the baseline data revealed several misconceptions among the workers about OCP use. Many believed that long-term use of OCP could be harmful, and only 21 percent believed that women could use OCP through out their reproductive life if no contraindications are noted. Less than one-fifth were correctly aware of the action to be taken if a woman misses pills for two consecutive days. These misconceptions and knowledge gaps were also discussed during training and the right answers were provided to them. In general the workers had poor counseling skills (Figure 3 ).

A post-training test conducted immediately after the two-day training showed a major increase in their ECP knowledge (Figure 3). The immediate evaluation after the first training also revealed that some providers were still confused about OCP use.

Evaluation of the training program four months after the first training showed a high retention of ECP knowledge. Practically all providers were able to tell how to correctly use the ECP. Also, most of them were able to name at least five brands of regular oral contraceptive pills that could be used as ECP if a dedicated ECP product was not available. Furthermore, 72-93 percent of the workers were able to give detailed and correct answers to all the questions on how the Figure 3: Percentage of Correct Responses given by Providers Who Participated in Pre-training, Immediate and Post-training Evaluation

Knows correctly

what to do if

Tw o consecutive pills are missed

Three consecutive pills are missed

OCP could take life long

Know how to use ECP

Privacy could also violated by the presence of person from the same sex

$\square$ Pre-training $\square$ Immediate $\square$ Post-training

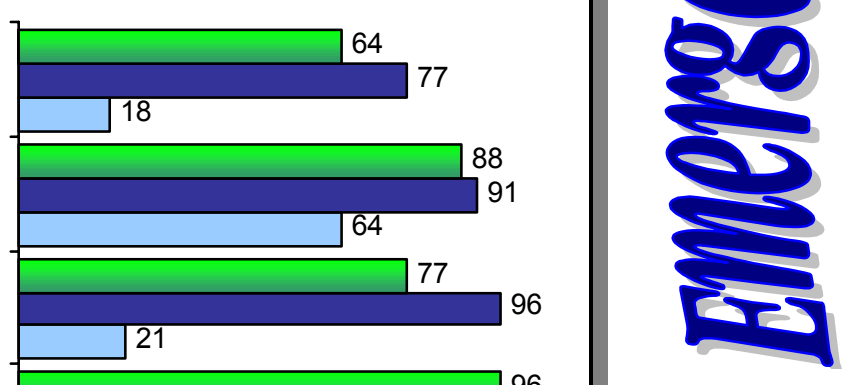
specific brand of oral contraceptive pills could be used as ECP (Table 1). A higher proportion of workers were able to give correct answers for those OCP that they were stocking. 
The educational qualification of the provider and previous training in family planning methods were not found related to the correct knowledge of ECP use. This indicates that, with the exception of the depot holders who generally had the lowest level of education, understanding and correctly communicating use of ECP is not a problem.

The providers evaluated the whole training process as useful

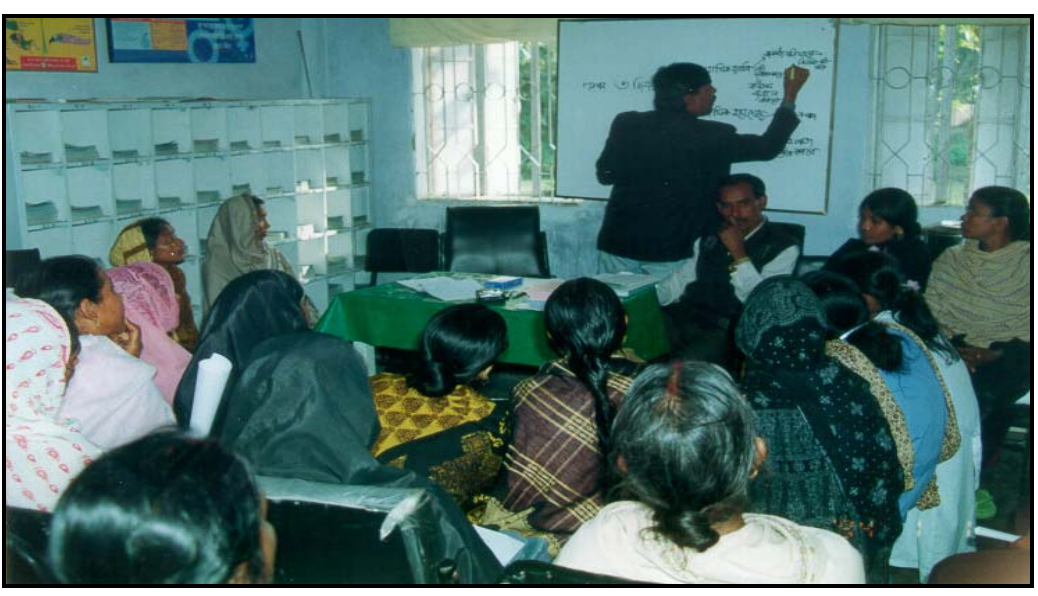
and gave a high rating to the various teaching/counseling aids developed for the training. The evaluation also shows that the training was successful in removing several misconceptions among the workers about OCP use and strengthening their counseling skills (Figure 3 ).

Data collected from the providers during the post-test evaluation survey revealed that 93 percent of the providers reported that the majority of the women who used ECP after unprotected intercourse returned to a regular contraceptive method. This indicates that the workers were able to provide correct information about ECP to their clients and counsel them to use ECP mainly as a back-up support. However, a final conclusion about this can be made only after examining the results of the follow-up survey of the clients, which is currently being analyzed.

\section{Table 1: Retention of Knowledge Gained about ECP--Percentage of Workers Who Mentioned Correct Answers to All Questions on OCP that Could Be Used as ECP*}

\begin{tabular}{|l|c|c|c|c|c|}
\hline & \multicolumn{2}{|c|}{ Immediate Evaluation } & \multicolumn{2}{|c|}{ Final evaluation } & \\
\hline OCP brand & $\begin{array}{c}\text { Percentage of } \\
\text { workers named } \\
\text { the specific } \\
\text { brand of OCP as } \\
\text { possible ECP }\end{array}$ & $\begin{array}{c}\text { Percentage of } \\
\text { workers gave } \\
\text { correct } \\
\text { answer** }\end{array}$ & $\begin{array}{c}\text { Percentage of } \\
\text { workers named } \\
\text { the specific } \\
\text { brand of OCP as } \\
\text { possible ECP }\end{array}$ & $\begin{array}{c}\text { Percentage of } \\
\text { workers gave } \\
\text { correct } \\
\text { answer** }\end{array}$ & $\begin{array}{c}\text { Retention rate } \\
\text { of correct } \\
\text { knowledge }\end{array}$ \\
\hline Shukhi & 100 & 97 & 100 & 93 & 96 \\
\hline Marvelon & 82 & 88 & 100 & 72 & 83 \\
\hline Femicon & 96 & 97 & 100 & 84 & 88 \\
\hline Nordette 28 & 94 & 94 & 100 & 80 & 86 \\
\hline Ovastat & 83 & 79 & 100 & 83 & 105 \\
\hline $\mathrm{N}$ & 238 & 238 & 245 & 245 & \\
\hline
\end{tabular}

* In the base line survey only 4 workers had correct answers

** Correct knowledge= workers had correct knowledge of number of doses, pills per dose, interval between two doses and timing within which the first dose must be taken.

\section{Lessons Learned}

- The study indicates that grass-roots family planning workers including depot holders, can be easily trained to educate and provide ECP services in the community.

- After training, workers are able to communicate correct information about ECP to their clients.

- The training model developed for the present project--a two- day initial training and a half- day reorientation after the workers have provided the services for one month--is effective and sufficient. 
- ECP training can be easily integrated in the existing training program for the FP program. In such case, ECP training could be reduced to a half-day session.

- The trainer's manual, ECP brochures and other teaching aids developed for the project were found useful and effective. All of them could be easily adopted for introducing ECP at the national level.

- To avoid confusion, ECP should

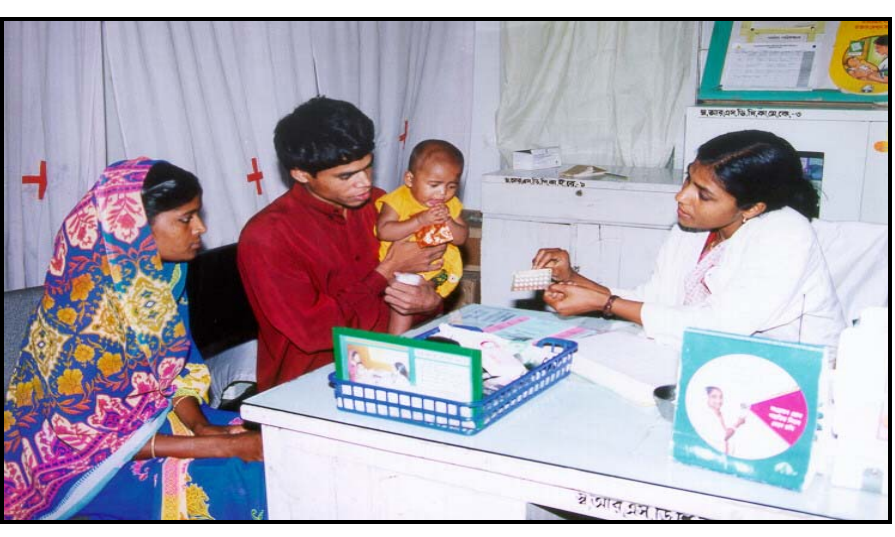
be promoted as a dedicated product.

- Prevailing misconceptions about OCP and its use should be taken seriously by the program to improve the continuation rate of oral contraceptive pills.

\section{References}

Chowdhury, Syeeda Nahid Mukith, Sharif M. I. Hossain and Nazmul Huda. 1998. "Knowledge, Attitude and Practices on EC among Selected Health Care Providers and Drug Sellers in Dhaka City." In Emergency Contraception Workshop Proceedings. Dhaka, Bangladesh: Population Council.

Chowdhury, T. A. 1998. "Emergency Contraception: Service Providers' Concerns and Considerations." In Emergency Contraception Workshop Proceedings. Dhaka, Bangladesh: Population Council.

Khan, M. E. and Sharif M. I. Hossain. 2001. "Introducing Emergency Contraception in Bangladesh." In Research Update No 1. Dhaka, Bangladesh: Population Council.

UNDP/UNFPA/WHO/World Bank Special Programme of Research, Development and Research Training in Human Reproduction. 2001. "Use of Emergency Contraception Pills Could Halve the Induced Abortion Rate in Shanghai, China." In Social Science Research Policy Briefs. Series 2. No 1.

\section{Suggested Citation}

Khan, M. E. and Sharif Mohammed Ismail Hossain. "Training Service Providers on Emergency Contraception: Lessons Learned from an OR Study." Research Update 2, March 2002. Dhaka, Bangladesh: Population Council/FRONTIERS.

This Research Update has been prepared by M. E. Khan and Sharif Mohammed Ismail Hossain, Population Council. Office address: House CES (B) 21, Road 118, Gulshan, Dhaka 1212, Bangladesh. Tel: 8821227, 8826657, Fax: 8823127, e-mail: frontiers@pcdhaka.org

The study was conducted in collaboration with the Directorate of Family Planning, Government of Bangladesh (Dr. A. K. M. Kamal), Pathfinder International/RSDP (Dr. Shabnam Shahnaz)) and John Snow, Inc./UFHP (Dr. Nadira Sultana).

This publication was made possible by the Office of Population of the U. S. AGENCY FOR INTERNATIONAL DEVELOPMENT (USAID), under the terms of the Frontiers in Reproductive Health Program Cooperative Agreement Number HRN-A-00-98-00012-00. The opinions expressed herein are those of the author (s) and do not necessarily reflect the views of USAID. 